\title{
Topical Referents for Individuals and Possibilities
}

\author{
Maria Bittner \\ Rutgers University
}

\section{Introduction}

In a classic paper Partee (1973) noted detailed referential and anaphoric parallels between tenses and pronouns in English. Since then these parallels have been successfully analyzed in terms of domain-neutral principles of discourse reference and anaphora - most fully developed in Kamp \& Reyle (1993) - which apply uniformly to referents of various logical types. These include ordinary individuals (the kings and cabbages sort) as well as times, events and states.

The referential parallel has long been known to extend even further, to the modal domain - a discovery due to Kaplan (1978). More recently, the anaphoric parallel has likewise been extended. At the intuitive level, there is now consensus that individuals and possibilities are on a par for the purposes of reference and anaphora. But it remains an open question whether the formal analogue of an individual in the modal domain - in intuitive terms, a possibility - is a possible world (as in Kaplan 1978, Schlenker 1999), a class of possible worlds (Stone 1997) or a dynamic update (e.g., Frank \& Kamp 1997).

Orthogonal to this issue, it has also been observed that in all semantic domains some referents are more central than others, in the sense of the centering theory of Grosz et al (1995). For example, Stone \& Hardt (1997) show that 'sloppy' ellipsis in English generalizes across all semantic domains, and that it can be uniformly analyzed as strict discourse anaphora to center-sensitive referents, with the illusion of sloppiness due to center shift.

In this paper I first present crosslinguistic evidence that the parallels between individuals and possibilities are indeed pervasive. Moreover, the centering parallels are even more detailed than has so far been recognized. These parallels favor the view that a possibility - the modal analogue of an individual - is best analyzed as a class of possible worlds, as in Stone (1997). Adopting this view, I then develop a semantic representation language, which I call Logic of Change with Centered Worlds, in which the observed cross-domain parallels can be formally explicated. This logic combines theoretical insights drawn from three sources: the Logic of Change of Muskens (1995), the extension to modal anaphora due to Stone (1997), and the related Logic of Change with Centering presented in Bittner (2001).

\section{Individuals and Possibilities in Natural Languages}

\subsection{Reference and Anaphora}

The sentences of (1) illustrate the referential parallel between pronouns and modals in English. Sentence (1a) was uttered by a receptionist in a dental clinic who saw me sitting in the waiting room. We had never met before. But since we both knew that the clinic had only one dentist and that this dentist was female, our contextual common ground made it easy to identify the intended referent of the pronoun she.

a. She'll be with you shortly.

b. My neighbours would kill me. 
Stone (1997) points out a similar referential use of the counterfactual modal would in (1b). In the context he describes the speaker is in a store with hi-fi equipment looking longingly at a high-powered system. The natural interpretation is that the modal refers to the contextually salient possibility that the speaker might buy this system and play it at the intended strength. What (1b) asserts is that in all the closest worlds of this prominent possibility the speaker gets killed by the neighbours.

In the examples of (1) the intended referent is prominent in virtue of the extralinguistic context. Alternatively, contextual salience can be raised by recent mention in discourse. For example, in (2) the bracketed phrases introduce discourse referents for an individual in (a) or a possibility in (b). These referents are then prominent enough to be picked up by anaphoric proforms of matching logical type - the pronoun she in (a) and the counterfactual modal would in (b).

a. [A doctor] just came in and she'll be with you shortly.

b. [If I bought this system], my neighbours would kill me.

Stone (1997) develops a DRT-style theory of modal reference and anaphora in English by hypothesizing that nouns and verbs have an extra argument slot for possibilities. The motivation he gives is purely theoretical - this is what he needs to make his story work. While English is unrevealing in this respect, other languages - including West Greenlandic Eskimo and my native Polish — provide striking morphological support.

Just as Stone's hypothesis would predict, the morphology at issue - to wit, case and mood inflections - occurs on both nouns and verbs, as illustrated by the paradigm in (3)-(6) below. This paradigm suggests a uniform semantics for inflectional morphemes - namely, that they are morphological realizations of the central arguments of the stem. For agreement inflections, this is just the old idea that they are semantically similar to pronouns. What is new is the extension of this idea to the possibility argument which, by hypothesis, nouns and verbs also have. In Polish and Eskimo the possibility argument is morphologically realized by case or mood. Strikingly, these two inflections exhibit the same range of uses referential and anaphoric - as the English modal would in (1b) and (2b).

That is, parallel to the referential use of would in (1b) we find referential uses of case and mood inflections, exemplified in (3) and (4). ${ }^{1}$

\section{Real object (NOM) vs. Irrealis object (OBL)}

\begin{tabular}{|c|c|c|}
\hline $\begin{array}{l}\text { Woda. } \\
\text { water.NOM } \\
\text { (pointing) }\end{array}$ & $\begin{array}{l}\text { Wod-y! } \\
\text { water-GEN } \\
\text { (in a desert) }\end{array}$ & Polish \\
\hline $\begin{array}{l}\text { Imiq. } \\
\text { water.NOM } \\
\text { (pointing) }\end{array}$ & $\begin{array}{l}\text { Imir-mik! } \\
\text { water-MOD } \\
\text { (in a desert) }\end{array}$ & WG Eskimo \\
\hline
\end{tabular}

Real event (IND) vs. Irrealis event (INF)
a. Pracu-ję. work-PRS.1sG
'I am working'
Pracowa-c!
work-INF
'Work!'
Polish
b. Suli-vu -nga. work-IND ${ }^{1}$-1SG 'I am working.'
Suli-llu-tit! work-INF-2SG 'Work!'


First, consider case in (3). Both Polish and WG Eskimo allow a bare nominative (NOM) to refer to reality. And both contrast this with a designated oblique genitive (GEN) in Polish, modalis (MOD) in WG Eskimo - which refers to some other contextually salient possibility. So, for example, the bare nominative nouns of (3) can be uttered while pointing to a body of water to express the proposition that in reality this is water. In contrast, the bare obliques could be used in a desert to convey that in the worlds of the speaker's desire the concept currently on his mind is water. $^{2}$ This pattern extends to verbal predicates, as shown in (4). Here the indicative mood asserts the existence of a work event in reality, whereas the infinitive indicates that the existence of such an event is desired. ${ }^{3}$

Turning now to the parallel with the anaphoric use of would in (2b), irrealis case and mood inflections can likewise be anaphoric. This is shown in (5) and (6), where the intensional verbs, 'want' or 'promise', play the same role as the if-clause in (2b). That is, they set up a referent for a possibility - the class of worlds the speaker would rather be in, or the class of worlds where the promise is fullfilled. This possibility serves as the antecedent for the anaphoric inflection - oblique or infinitive - on the complement of the intensional verb.

Anaphoric Obliques
a. Chc-e [want]-PRS.1SG
wod-y.
Polish
'I want water.'
b. Imir-mik
water-MOD
'I promised him water.'
WG Eskimo

(6) Anaphoric Infinitives
a. Chc-ę [want]-PRS.1sG
pracowa-c.
Polish
'I want to work.'
b. Suli-ssa-llu-nga niriursur-pa-ra. work-EXP-INF-1SG [promise]-IND ${ }^{2}$-1SG.3SG
'I promised him to work.'
WG Eskimo

In summary, the hypothesis that individuals and possibilities are on a par in lexical argument structures is not only theoretically attractive. It also receives empirical support from inflectional patterns which languages as diverse as Polish and WG Eskimo converge on. Under this hypothesis, it is not an accident that the same obliques crop up in (3) and (5), and the same infinitives in (4) and (6). These case and mood inflections presuppose that the possibility argument of the stem is irrealis. They are modal proforms, similar to the English modal would, so it is expected that they will have both referential and anaphoric uses. Neither is it an accident that case and mood inflections tend to cluster with person agreement. Agreement markers, too, are proforms which realize central arguments of the stem. The only difference is in logical type - arguments which trigger person agreement are individuals, not possibilities.

\subsection{Center vs. Periphery: Correlative Topic-Comment Structures}

So far, crosslinguistic evidence confirms the referential and anaphoric parallels uncovered by English-based research and the crosslinguistic work of Schlenker 
(1999). I now turn to a more radical claim, that the semantic parallels between individuals and possibilities are even more detailed than has so far been recognized.

Particularly dramatic evidence comes from centering parallels in biclausal topic-comment structures known as correlatives. Crosslinguistically the details vary but the stable pattern is that the dependent clause introduces one or more topical referents to be commented on by the matrix clause, where each topical referent must be picked up by - correlated with - an anaphoric proform.

In English this structural type is arguably instantiated by conditionals - the dependent if-clause sets up a topical possibility, which is linked to the modal anaphor then in the matrix comment. Crucially, many languages allow analogous readings with topical individuals, as in the ambiguous Warlpiri correlative (7) (first noted by Hale 1976).

$$
\begin{array}{lccc}
\text { Maliki-rli } & k a j i-n g k i & \text { yarlki-rni nyuntu } \\
\text { [dog-ERG } & S T-3 \text { SG.2SG } & \text { bite-NPST you] } \\
\text { ngula-ju } & \text { kapi-rna } & \text { luwa-rni ngajulu-rlu. } \\
\text { DEM-TOP } & \text { FUT-1SG.3SG shoot-NPST } & \text { me-ERG }
\end{array}
$$

A. 'As for the dog that bites you, I'll shoot it.'

B. 'If a dog bites you, then I'll shoot it.'

(individual-centered)

(possibility-centered)

The dependent clause of (7) — with the complementizer kaji, glossed 'ST' for 'same topic' - introduces a topical referent of some type. On reading (7A) the topic is a contextually prominent individual, and on reading (7B), a prominent possibility. In either case, the topical referent is picked up in the matrix comment by a topicoriented anaphoric demonstrative ngula-ju, which is likewise type-neutral. So depending on the context, the topic of (7) may be either the most prominent dog which bites the addressee or the closest possibility that a dog may bite. The correlated comment is that the speaker will shoot the topical dog, or that in every world of the topical possibility the speaker will shoot whatever dog bites there.

The fact that one and the same sentence can have both of these readings suggests that they have essentially the same semantic representation, up to logical type. This, in a nutshell, is the analysis I will propose. In particular, both readings of the ambiguous Warlpiri correlative (7) involve a type-neutral operation which I will call topical maximization. On the individual-centered reading (7A), this operation selects the greatest and most central element from the contextual set of biting dogs. On the possibility-centered reading (7B), it selects the greatest and closest element from the contextual set of possibilities with a biting dog. So topical maximization draws the following point-for-point parallels across the two domains.

$(\sim)$

Individual domain
atom
individual (consisting of atoms)
most central
part-whole order $\subseteq$
$\subseteq_{e}$-greatest individual

$\begin{array}{ll} & \text { Modal domain } \\ \sim & \text { world } \\ \sim & \text { possibility (consisting of worlds) } \\ \sim & \text { closest } \\ \sim & \text { part-whole order } \subseteq_{\mathrm{w} t} \\ \sim & \subseteq_{\mathrm{w} t} \text {-greatest possibility }\end{array}$

To some extent, these parallels have been hinted at in informal remarks by typologists (e.g., Andrews 1975, Hale 1976, Haiman 1978). There is even a hint of a possible theoretical approach (von Fintel 1994). But, as far as I can see, there is still no formally explicit semantic theory which can draw these parallels. To be sure, there are theories of maximization for definite noun phrases (e.g., Sharvy 1980, Link 1983, Groenendijk et al 1995) or individual-centered correlatives (e.g., 
Cooper 1979, Dayal 1996, Grosu \& Landman 1998) or conditional correlatives (e.g., Frank \& Kamp 1997, Stone 1997). But all of these theories are stated in domain-specific terms which make it difficult to capture the cross-domain parallels dramatically revealed by correlatives with ambiguous centers, such as Warlpiri (7). ${ }^{4}$

Further details are revealed by Indo-Aryan languages, Marathi (8)-(9) (from Andrews 1975) and Hindi (10)-(11) (from my own field work). In Marathi, unlike in Warlpiri, correlative morphology is sensitive to type, as illustrated by the $j / t$ paradigm in (8).

$$
\begin{aligned}
& \text { ja 'which' jevha 'when' jithe 'where' ...jEr 'if' jEri 'although' } \\
& \text { tya 'that' tevha 'then' tithe 'there' ...tEr 'then' tEri 'even so' }
\end{aligned}
$$

Also, each topical referent is marked in the dependent clause by a typed $j$ word - e.g., ja ...ja in (9a), jEr in (9b) - and is picked up in the matrix comment by a related $t$-word. Thus, (9a) is about a pair of topical individuals - to wit, the contextually most prominent pair of a boy and a girl he hated. Similarly, (9b) is about a topical possibility - the closest worlds where the relevant man comes.
a. Ja mula-ni ja muli-shi dues kela, [which boy-ERG which girl-GEN hatred did] 'As for that boy and the girl he hated,
tya-ni ti-la mar-li.
that.M-ERG that.F-ACC kill-PST he killed her.'
b. JEr to ithE yel, [if that.M here comes]
'If he comes here,
$t E r$ miN tya-la goli mar-in.
then me.ERG that.M-ACC bullet kill-FUT
then I'll kill him.'

In a different way, then, Marathi points to the same parallel as Warlpiri, strengthening the motivation for a domain-neutral representation of correlative topics. The Indo-Aryan evidence further shows that the desired representation must generalize not only across semantic domains but also across $n$-tuples of topical referents. In particular, topical maximization must apply correctly to such $n$-tuples.

For instance, in Marathi (9a) and Hindi (10) - with two j-marked topical NPs in the dependent clause - topical maximization must select the greatest and most central element from the contextual set of pairs of topical referents that satisfy the dependent clause. Moreover, in a well-formed correlative each coordinate of the $n$-tuple of topical referents introduced by the dependent clause must be picked up by an anaphor in the matrix comment (as in (9a) and (10)). Note that the correlation need not be one-one because split antecedents are permitted (as noted by McCawley 1992, and illustrated by the Hindi example (10)).

$$
\begin{aligned}
& \text { Jo laRkii jis laRke-se baat kar rahii hai, ve dost haiN. } \\
& \text { [which girl which boy-INS talk do PRG is] those friends are } \\
& \text { 'As for the girl and the boy she talking to, they are friends.' }
\end{aligned}
$$

What is not permitted are dangling topical referents in the dependent clause which the matrix comment fails to address. Hence the ill-formedness of (11a), 
where the comment fails to say anything about the topical boy. The minimally contrasting $(1 \mathrm{~b})$ is good again because the offending topical $j$-determiner, $j i s$, is replaced with $e k$ 'one'. With this referent removed from the center of attention, the matrix comment is now properly about the $j$-marked topic.

a. * Jo laRkii jis laRke-se baat kar rahii hai, vo lambii hai. [which girl which boy-INS talk do PRG is] that tall.SG.F is. ('As for the girl and the boy she's talking to, she is tall.')

b. Jo laRkii ek laRke-se baat kar rahii hai, vo lambii hai. [which girl one boy-INS talk do PRG is] that tall.SG.F is 'As for the girl who's talking to a boy, she is tall.'

In general, the centering theory of Grosz et al (1995) provides a natural approach to correlative topics. Topical discourse referents - syntactically $j$-marked in Indo-Aryan and semantically distinguished by topical maximization as well as aboutness presuppositions - are in the center of attention and in contrast to peripheral referents. This semantic contrast is akin to focal vs. peripheral vision.

This basic idea can be made formally precise by extending the Logic of Change with Centering of Bittner (2001). This logic - unlike competing formal theories of centering (e.g., Stone \& Hardt 1997) - crucially allows for structured centers, with $n$-tuples of central dref's of any type. This is needed, for instance, in (9a) and (10) to explicate the intuition that the topic is a pair of central individuals who stand in the relevant relation. We also need to allow for topics of other types, including possibilities. Toward this end, we will add possible worlds, as in Stone (1997), who also builds on the Logic of Change of Muskens (1995). This is done in section 2. As will be shown in the subsequent sections, the resulting semantic representation language will enable us to explicate the point-for-point parallels between individuals and possibilities that languages all over the globe converge on.

\section{Logic of Change with Centered Worlds}

The ontology of our Logic of Change with Centered Worlds is laid out in Table 1, which also gives an overview of the key terms and the abbreviatory conventions.

Table 1.

\begin{tabular}{|c|c|c|c|c|c|c|}
\hline Type & Abbr. & Name of objects & ${ }^{\top}$ Var & ${ }^{1} \operatorname{Var}$ & ${ }^{\top}$ Dem & ${ }^{\perp}$ Dem \\
\hline$t$ & & truth values & & & & \\
\hline $\mathbf{w}$ & & worlds & & $w$ & & \\
\hline $\mathbf{S}$ & & stacks & & $c, d$ & & \\
\hline $\mathbf{w} \times \mathbf{s} \times \mathbf{s}$ & $s$ & centered worlds & & $i, j, h$ & & \\
\hline & & updates & & & & \\
\hline$e$ & & individuals & $\mathbf{x}$ & $x$ & & \\
\hline $\mathbf{w} t$ & $\omega$ & possibilities & $\mathbf{p}$ & $p$ & & \\
\hline we & $E$ & static $e$-concepts & $\mathbf{y}$ & $y$ & & \\
\hline $\mathbf{w}(\mathbf{w} t)$ & $\Omega$ & static $\omega$-concepts & $\mathbf{q}$ & $q$ & & \\
\hline sa & & $\begin{array}{l}\text { dynamic } a \text {-concepts, } \\
a \in\{e, \omega, E, \Omega\}\end{array}$ & & & $\mathbf{d} a_{0}$ & $d a_{0}$ \\
\hline
\end{tabular}


In addition to the familiar basic types $-t$ for truth values, $\mathbf{w}$ for possible worlds, and $e$ for individuals - there is one new basic type, $\mathrm{s}$, for stacks of prominence-ranked discourse referents (dref's for short). A centered world intuitively, a world viewed from a particular perspective - is formally a riple of a world and two stacks. These, too, are ranked by prominence - the top stack ( T), for dref's in the center of attention, outranks the bottom stack $(\perp)$, for peripheral dref's. Updates are modelled as transitions from one centered world to another. This articulates the intuition that an update can affect both the factual information (modelled by the world coordinate, as in Stalnaker 1975) and relative prominence in the center of attention and background (modelled by the two stacks of dref's).

In contrast to classical dynamic systems (such as Kamp \& Reyle 1993), dref's are not variables, but actual semantic objects that are prominent enough to be referred to by anaphoric demonstratives (as in Dekker 1994, Bittner 2001). For our purposes, we need four types of dref's - individuals, possibilities, individual concepts, and possibility concepts (types $e, \omega, E$, and $\Omega$ ). Note that the concept of a possibility is an accessibility relation over possible worlds $(\Omega:=\mathbf{w}(\mathbf{w} t))$.

Variables, on this view, are merely tools for stacking dref objects. Since we have two stacks - top ( $T$ ) and bottom $(\Lambda)$ - we need two sets of variables for stacking dref's and two sets of demonstratives for retrieving them. More precisely, dref's are added to the top stack by top variables $\left(\mathbf{x}, \mathbf{p}, \ldots \in{ }^{\top}\right.$ Var $)$ and to the bottom stack by bottom variables $\left(x, p, \ldots \in{ }^{\perp}\right.$ Var $)$. Similarly, dref's are retrieved from the top stack by top demonstratives, of the form $\mathrm{d} a_{n}$, and from the bottom stack by bottom demonstratives, of the form $d a_{n}$. For all demonstratives, top and bottom, the type index $a \in\{e, \omega, E, \Omega\}$ indicates the type of dref to be retrieved, and the numerical index $n$, how many dref's of that type are to be skipped first. So anaphoric demonstratives identify their antecedents not by arbitrary indices, but by their current prominence rank, which depends on three factors - the stack (center vs. background), the type and the rank among the objects of that type on that stack.

Stacks are thus intended to model sequences of prominence-ranked dref objects. But formally they are just primitive objects in the model. To make sure that they behave as intended we will constrain them by axioms which formally define two projection functions: $\pi_{n}$, which returns the $n$ 's coordinate of the input, and $\pi_{a}$, which returns the result of retaining just the coordinates of type $a$. We abbreviate $\pi_{n}\left(\pi_{a}(c)\right)$ as $\pi_{n, a}(c)$ (n'th $a$-dref on stack $c$ ), and $\{e, \omega, E, \Omega\}$ as $\Theta$ (types of dref's).

The first two axioms ensure that the identity of a stack is fully determined by its projections, and that any potential dref object - i.e., any individual, possibility, individual concept, or possibility concept - can be added to any stack.

AX1 $\forall c \forall d\left(\forall n \forall a \in \Theta\left(\pi_{n, a}(c)=\pi_{n, a}(d)\right) \rightarrow c=d\right)$

$\mathrm{AX} 2 \quad \forall c \forall a \in \Theta \forall v_{a} \exists d\left(\pi_{1}(d)=v_{a} \wedge \forall n\left(n>1 \rightarrow \pi_{n}(d)=\pi_{n-1}(c)\right)\right)$

Axiom 1 is straightforward - if two stacks agree on all of their projections, then it must be the same stack. Axiom 2 ensures that for any stack and dref object there is another stack with that object on top and everything below it as on the first stack.

To state the remaining axioms we need to define an operation on centered worlds which returns the recentered world that results from adding a new dref object to the top or bottom stack. This is done in definition 1. Clause (i) says that, for any centered world $i$, adding a new dref object to the top stack of $i, \mathrm{~T}_{i}$, leaves the world coordinate, $w_{i}$, and the bottom stack, $\perp_{i}$, unchanged, whereas on the top stack the new dref object is most prominent and all prior dref's are demoted one notch. Mutatis mutandis, adding a new dref to the bottom stack has analogous effects. These are spelled out in clause (ii). 
DEFINITION 1 (Recentering). Given centered worlds $i=\left\langle w_{i}, \top_{i}, \perp_{i}\right\rangle, j=\left\langle w_{j}, \top_{j}, \perp_{j}\right\rangle$, and variables $\mathbf{u}_{a} \in{ }^{\top} \operatorname{Var}_{a}, u_{a} \in{ }^{\perp} \operatorname{Var}_{a}$ :

i. $\left(\mathbf{u}_{a} \cdot i\right)=j$ iff

$$
w_{i}=w_{j} \wedge \perp_{j}=\perp_{i} \wedge \pi_{1}\left(\top_{j}\right)=\mathbf{u}_{a} \wedge \forall n\left(n>1 \rightarrow \pi_{n}\left(\top_{j}\right)=\pi_{n-1}\left(\top_{i}\right)\right)
$$

ii. $\left(u_{a} \cdot i\right)=j$ iff

$$
w_{i}=w_{j} \wedge \top_{j}=\top_{i} \wedge \pi_{1}\left(\perp_{j}\right)=u_{a} \wedge \forall n\left(n>1 \rightarrow \pi_{n}\left(\perp_{j}\right)=\pi_{n-1}\left(\perp_{i}\right)\right)
$$

The remaining axioms articulate the intuition that prominence rank is relative to logical type. For intuitively, adding a new dref object of a certain type to a given stack (say, a new topical possibility) demotes in prominence only older dref's of the same type on that stack (i.e., old topical possibilities). It has no bearing on the prominence rank of dref's of other types (e.g., topical individuals or concepts). Axioms 3 and 4 ensure this for the top stack and axioms 5 and 6, for the bottom stack. Formally, they do this by constraining the projection function $\pi_{a}$, which returns the result of retaining just the coordinates of type $a$ from the input stack.

AX3 $\quad\left(\mathbf{u}_{a} \cdot i\right)=j \rightarrow \pi_{1, a}\left(\top_{j}\right)=\mathbf{u}_{a} \wedge \forall n\left(n>1 \rightarrow \pi_{n, a}\left(\top_{j}\right)=\pi_{n-1, a}\left(\top_{i}\right)\right)$

$\mathrm{AX} 4 \quad\left(\mathbf{u}_{a} \cdot i\right)=j \rightarrow \forall b \in \Theta\left(b \neq a \rightarrow \pi_{b}\left(\top_{j}\right)=\pi_{b}\left(\top_{i}\right)\right)$

AX5 $\quad\left(u_{a} \cdot i\right)=j \rightarrow \pi_{1, a}\left(\perp_{j}\right)=u_{a} \wedge \forall n\left(n>1 \rightarrow \pi_{n, a}\left(\perp_{j}\right)=\pi_{n-1, a}\left(\Lambda_{i}\right)\right)$

AX6 $\quad\left(u_{a} \cdot i\right)=j \rightarrow \forall b \in \Theta\left(b \neq a \rightarrow \pi_{b}\left(\perp_{j}\right)=\pi_{b}\left(\Lambda_{i}\right)\right)$

We are now ready to interpret the terms of our logic (definition 2). Taking cue from natural language morphology - e.g., the $j / t$ paradigm (8) of Marathi dref-introducing variables are not conflated with dref-retrieving demonstratives.

DEFINITION 2 (Interpretation of terms)

$$
\begin{aligned}
& \text { i. } t^{\circ}:=\lambda i w t \quad \text {,if } t \in M E_{a}, a \in\{e, \omega\} \\
& :=\lambda i w t w \quad \text {,if } t \in M E_{a}, a \in\{E, \Omega\} \\
& \text { ii. } \mathbf{d} a_{n}^{\circ}:=\lambda i w \pi_{n+1, a}\left(\top_{i}\right) \quad \text {, if } a \in\{e, \omega\} \\
& :=\lambda i w \pi_{n+1, a}\left(\top_{i}\right) w \text {, if } a \in\{E, \Omega\} \\
& d a_{n}^{\circ}:=\lambda i w \pi_{n+1, a}\left(\perp_{i}\right) \quad \text {, if } a \in\{e, \omega\} \\
& :=\lambda i w \pi_{n+1, a}\left(\perp_{i}\right) w \text {, if } a \in\{E, \Omega\}
\end{aligned}
$$

More precisely, clause (i) interprets constants and variables in the usual way (as in Stone 1997). By clause (ii), anaphoric demonstratives are interpreted as pointers to fixed stack positions (as in Bittner 2001). For example, given a centered world $i$, the demonstrative $\mathbf{d} \omega_{0}$ will retrieve the highest possibility from the top stack of $i$. Similarly, $d E_{0}$ will retrieve the highest individual concept from the bottom stack of $i$. In intuitive terms, $\mathbf{d} \omega_{0}$ retrieves the currently most prominent topical possibility, and $d E_{0}$, the most prominent individual concept from the current background. Since, by default, all anaphora is top level - i.e., it normally targets the most prominent dref object of the relevant type on the relevant stack - index 0 is suppressed in what follows (i.e., we write $\mathbf{d} a$ for $\mathbf{d} a_{0}$, and $d a$ for $d a_{0}$ ). 
Canonical conditions and DRS boxes are built according to the BNF syntax given in definition $3 .^{5}$ The only syntactic innovation, adapted from Stone (1997), is that relational conditions are relativized to a modal domain - the subscripted term $\mathbf{t}$, which can be of type $\omega:=\mathbf{w} t$ (possibility) or $\Omega:=\mathbf{w}(\mathbf{w} t)$ (possibility concept).

\section{DEFINITION 3 (Canonical conditions and boxes)}

$$
\begin{aligned}
& \text { i. } C:=R_{\mathrm{t}}\left\langle t_{1}, \ldots, t_{n}\right\rangle\left|\left(t_{1}=t_{2}\right)\right|(C, C) \\
& \text { ii. } D::=\left[v_{1} \ldots v_{n} \mid C\right]|[\mid C]|(D ; D)
\end{aligned}
$$

Semantically, conditions are properties of centered worlds and boxes, transitions from one centered world to another (definition 4, à la Muskens 1995).

\section{DEFINITION 4 (Interpretation of conditions and boxes)}

$$
\text { i. } \begin{aligned}
R_{\mathrm{t}}\left\langle t_{1}, \ldots, t_{n}\right\rangle & :=\lambda i \forall w\left(\mathbf{t}^{\circ} i w_{i} w \rightarrow R_{w}\left(t_{1}{ }^{\circ} i w, \ldots, t_{n}{ }^{\circ} i w\right)\right) \\
\left(t_{1}=t_{2}\right) & :=\lambda i\left(t_{1}^{\circ} i w_{i}=t_{1}{ }^{\circ} i w_{i}\right) \\
\left(C_{1}, C_{2}\right) & :=\lambda i\left(C_{1} i \wedge C_{2} i\right) \\
\text { ii. }\left[v_{1} \ldots v_{n} \mid C\right] & :=\lambda i j \exists v_{1} \ldots v_{n}\left(\left(v_{1} \ldots\left(v_{n} \cdot i\right)\right)=j \wedge C i\right) \\
{[\mid C] } & :=\lambda i j(i=j \wedge C i) \\
\left(D_{1} ; D_{2}\right) & :=\lambda i j \exists h\left(D_{1} i h \wedge D_{2} h j\right)
\end{aligned}
$$

Note that by clause (i), a relational condition relativized to a possibility must hold throughout that possibility (as in Stone 1997). For example, the condition get $_{\mathbf{q}}\langle m e, y\rangle$ is satisfied at a centered world $i$ iff in every world $w$ accessible from the world of $i, w_{i}$, via $\mathbf{q}$ the speaker gets the $w$-extension of the individual concept $y$.

In clause (ii), DRS boxes are interpreted as in Bittner (2001). Note that the order of the variables in the universe of a box is significant. It reflects the order of stacking, and so the prominence rank. Also, variables get bound off as soon as they have stacked their values. Only the stacked dref objects - individuals, individual concepts, possibilities, or possibility concepts - are retrievable by anaphoric demonstratives. Finally, a sequence of two updates, $\left(D_{1} ; D_{2}\right)$, is interpreted in the usual way - update the initial context with $D_{1}$ and then the result, with $D_{2}$.

\section{Examples: Obliques and Infinitives in Intensional Contexts}

We now have the formal tools we need to represent nominal and modal anaphora in complements of intensional verbs. For example, consider again the Polish examples (5a), with an oblique (genitive) complement, and (6a), with an infinitive.

The gloss of $(5 a)$ is repeated in $\left(5 a^{\prime}\right)$ together with the proposed semantic representation. Note that reality is represented by the totally realistic accessibility relation, $\mathbf{r}:=\lambda w w^{\prime}(w=w)$. Also, updates are numbered for ease of reference. The indicated compositional path assumes the bridging semantics of Bittner (2001). For now, my concern is not the compositional derivation, but rather the prior issue namely, the bottom line representation that the composition should aim for.

$$
\begin{aligned}
& { }^{(1)} \text { want-PRS.1SG } \\
& { }^{(1)}\left[\mathbf{q} y \mid \text { want }_{\mathbf{r}}\langle m e, \mathbf{q}\rangle, \text { get }_{\mathbf{q}}\langle m e, y\rangle\right] ;^{(2)}\left[\mid \text { water }_{\mathrm{d} \Omega}\langle d E\rangle\right]
\end{aligned}
$$


This sequence of updates affects the prominence hierarchy as well as factual information, in the manner spelled out in $\left(\mathrm{U}_{5 \mathrm{a}}\right)$ below:

$$
\begin{aligned}
& \left(\mathrm{U}_{5 \mathrm{a}}\right) \cdot{ }^{(1)}\left[\mathbf{q} y \mid \text { want }_{\mathbf{r}}\langle m e, \mathbf{q}\rangle, \text { get }_{\mathbf{q}}\langle m e, y\rangle\right] \\
& \equiv \text { (definition 4) } \\
& \lambda i j \exists \mathbf{q} y(\mathbf{q} \cdot(y \cdot i)=j \\
& \wedge \forall w\left(\mathbf{r}^{\circ} i w_{i} w \rightarrow \text { want }_{w}\left(m e^{\circ} i w, \mathbf{q}^{\circ} i w\right)\right) \\
& \left.\wedge \forall w\left(\mathbf{q}^{\circ} i w_{i} w \rightarrow \operatorname{get}_{w}\left(m e^{\circ} i w, y^{\circ} i w\right)\right)\right) \\
& \equiv \text { (definition 2, r, q } \in M E_{\Omega}, m e \in M E_{e}, y \in M E_{E} \text { ) } \\
& \lambda i j \exists \mathbf{q} y(\mathbf{q} \cdot(y \cdot i)=j \\
& \left.\wedge \forall w\left(\mathbf{r} w_{i} w \rightarrow \text { want }_{w}(\mathrm{me}, \mathbf{q} w)\right) \wedge \forall w\left(\mathbf{q} w_{i} w \rightarrow \operatorname{get}_{w}\left(m e, y_{w}\right)\right)\right) \\
& \equiv \quad\left(\text { reality } \mathbf{r}:=\lambda w w^{\prime}\left(w=w^{\jmath}\right)\right) \\
& \lambda i j \exists \mathbf{q} y(\mathbf{q} \cdot(y \cdot i)=j \\
& \left.\wedge \text { want }_{w_{i}}\left(m e, \mathbf{q} w_{i}\right) \wedge \forall w\left(\mathbf{q} w_{i} w \rightarrow \operatorname{get}_{w}\left(m e, y_{w}\right)\right)\right) \\
& \text { - }{ }^{(1)}\left[\mathbf{q} y \mid \text { want }_{\mathbf{r}}\langle m e, \mathbf{q}\rangle, \text { get }_{\mathbf{q}}\langle m e, y\rangle\right] ;{ }^{(2)}\left[\mid \text { water }_{\mathbf{d} \Omega}\langle d E\rangle\right] \\
& \equiv \quad\left(\text { definition } 4, \mathbf{d} \Omega:=\mathbf{d} \Omega_{0}, d E:=d E_{0}\right) \\
& \lambda i j \exists h(\exists \mathbf{q} y(\mathbf{q} \cdot(y \cdot i)=h \\
& \left.\wedge \text { want }_{w_{i}}\left(m e, \mathbf{q} w_{i}\right) \wedge \forall w\left(\mathbf{q} w_{i} w \rightarrow \operatorname{get}_{w}\left(m e, y_{w}\right)\right)\right) \\
& \wedge h=j \\
& \left.\wedge \forall w\left(\mathbf{d} \Omega_{0}{ }^{\circ} h w_{h} w \rightarrow \text { water }_{w}\left(d E_{0}{ }^{\circ} h w\right)\right)\right) \\
& \equiv \text { (eliminate } h \text {, definitions 1-2, rearrange) } \\
& \lambda i j \exists \mathbf{q} y(\mathbf{q} \cdot(y \cdot i)=j \\
& \wedge \text { want }_{w_{i}}\left(m e, \mathbf{q} w_{i}\right) \wedge \forall w\left(\mathbf{q} w_{i} w \rightarrow \operatorname{get}_{w}\left(m e, y_{w}\right)\right) \\
& \left.\wedge \forall w\left(\pi_{1, \Omega}\left(\top_{j}\right) w_{i} w \rightarrow \text { water }_{w}\left(\pi_{1, E}\left(\perp_{j}\right) w\right)\right)\right) \\
& \equiv(\mathrm{AX} 3-5, \text { rearrange }) \\
& \lambda i j \exists \mathbf{q} y(\mathbf{q} \cdot(y \cdot i)=j \\
& \left.\wedge \text { want }_{w_{i}}\left(m e, \mathbf{q} w_{i}\right) \wedge \forall w\left(\mathbf{q} w_{i} w \rightarrow \operatorname{get}_{w}\left(m e, y_{w}\right) \wedge \operatorname{water}_{w}\left(y_{w}\right)\right)\right)
\end{aligned}
$$

That is, in a more intuitive DRT style format, the two updates add the dref objects in $\left(R_{5 a}\right)$ with the conditions listed in $\left(C_{5 a}\right)$. Note that $\left(R_{5 a}\right)$ keeps track of center shifts by monitoring the reference of the demonstratives that occur in $\left(5 a^{\prime}\right)-$ $\mathrm{d} \Omega$ (that topical possibility concept) and $d E$ (that backgrounded individual concept).

$$
\begin{aligned}
& \left(\mathrm{R}_{5 \mathrm{a}}\right) \quad i \quad j=\left\langle w_{i}, \mathrm{\top}_{j}, \perp_{j}\right\rangle\left(\operatorname{after}^{(1)}\right) \quad h=j\left(\operatorname{after}^{(2)}\right) \\
& \mathbf{d} \Omega \quad \ldots \quad \lambda w^{\prime} w . \mathbf{W} w^{\prime} w \quad \lambda w^{\prime} w . \mathbf{W} w^{\prime} w \\
& d E \quad \ldots \quad \lambda w \cdot \mathbf{c}_{w} \quad \lambda w \cdot \mathbf{c}_{w} \\
& \left(\mathrm{C}_{5 \mathrm{a}}\right) \quad \cdot \text { want }_{w_{i}}\left(m e, \mathbf{W} w_{i}\right) \quad \bullet \forall w\left(\mathbf{W} w_{i} w \rightarrow \text { water }_{w}\left(\mathbf{c}_{w}\right)\right) \\
& \text { - } \forall w\left(\mathbf{W} w_{i} w \rightarrow \operatorname{get}_{w}\left(m e, \mathbf{c}_{w}\right)\right)
\end{aligned}
$$


Consider first the initial update, by the intensional verb 'want-PRS.1SG'. Starting from a centered world $i$, this update yields a recentered world $j$ if the factual conditions listed under $j$ in $\left(\mathrm{C}_{5 \mathrm{a}}\right)$ can be met and, otherwise, will eliminate $i$ from the common ground. Assuming that $i$ survives, two new dref's will be added - an $\omega$-concept to the top stack (added by $\mathbf{q}$ and in $\left(\mathrm{R}_{5 \mathrm{a}}\right)$ denoted by $\mathbf{W}$, for 'wish'), and an $e$-concept to the bottom stack (added by $y$ and denoted by c, for 'concept').

These two dref's must satisfy the conditions imposed by want $\langle\mathbf{r}$ ' $\mathbf{m}, \mathbf{q}\rangle$ and get $_{\mathrm{g}}\langle m e, y\rangle$. That is, from every real world the topical wish-concept $\mathbf{W}$ gives access to the worlds that the speaker would rather be in, and in all of these wish worlds the speaker gets the extension of the concept c. Now, recall that reality is modelled here as the totally realistic accessibility relation $\mathbf{r}$, which from each world gives access to that world only. So, from the perspective of $i$, 'every real world' amounts to just $w_{i}$. This reduction yields the two conditions listed under $j$ in $\left(\mathrm{C}_{5 \mathrm{a}}\right)$.

The intensional verb thus sets up the context for its oblique complement, 'water-GEN'. This does not add any new dref's - there is no recentering here but only new factual information. That is, this is a so-called test. To survive this test $w_{i}$ must meet the condition imposed by water $_{\mathrm{d} \Omega}\langle d E\rangle$. That is, in every world that can be reached from $w_{i}$ by the currently topical possibility concept, the extension of the main individual concept in the current background is water. The current stacks are those under $j$, so this amounts to the condition under $h-$ in each of the speaker's wish worlds that can be accessed from $w_{i}$ what he gets is water.

The analysis of (6a), with an infinitive complement, is analogous - as shown in $\left(6 a^{\prime}\right)$ - modulo a slight adjustment in the meaning of the verb. In a control structure it is not an implicit object concept but rather the subject individual - here, the speaker - that the verb sets up as a backgrounded dref to be picked up by the complement.

$$
\begin{array}{ll}
{ }^{(1)} \text { want-PRS.1SG } & { }^{(2)} \text { work-INF } \\
{ }^{(1)}\left[\mathbf{q} x \mid \text { want }_{\mathbf{r}}\langle x, \mathbf{q}\rangle, x=m e\right] ; & { }^{(2)}\left[\mid \text { work }_{\mathrm{d} \Omega}\langle d e\rangle\right]
\end{array}
$$

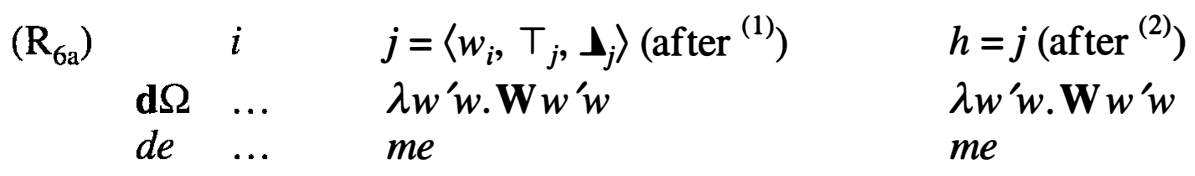

$\left(\mathrm{C}_{6 \mathrm{a}}\right)$

- want $_{w_{i}}\left(m e, \mathbf{W} w_{i}\right)$

- $\forall w\left(\mathbf{W} w_{i} w \rightarrow \operatorname{work}_{w}(m e)\right)$

However, the anaphora to a topical possibility concept - the speaker's wishes still proceeds just as before. This captures the anaphoric parallel between obliques and infinitives in intensional contexts. And if we just leave out the intensional verb and let the extralinguistic context do its work, then the referential parallel between bare obliques and infinitives - exemplified in (3) and (4) - also falls into place.

\section{Topical Maximization across Domains}

The Logic of Change with Centered Worlds also provides a natural framework for explicating domain-neutral generalizations about central dref's in correlative topiccomment structures. In particular, we can now draw a formal parallel between reference to the greatest and most central element within the contextual set of 
topical individuals that are so-and-so, and reference to the greatest and closest element within the contextual set of topical possibilities - classes of possible worlds - that are so-and-so. To draw this parallel, we define a domain-neutral operation of topical maximization which, applied to an update that introduces one or more central dref's, selects the greatest and closest dref's of the lot.

As a first step, we define two domain-neutral orders, $\leq$ and $\subseteq$, generalizing the proximity order of Lewis (1973) and the part-whole order of Sharvy (1980) to dref objects of all types. The definitions in (T1) and (T2) below make precise the cross-domain parallels $(\sim)$ informally drawn in section 1.2. Crucially, individuals made up of atoms (see Sharvy 1980, Link 1983) must be aligned with possibilities made up of worlds (Stone 1997). If possibilities are modelled as worlds simpliciter (e.g., Schlenker 1999), there is not enough structure for maximization parallels, and if they are modelled as updates (e.g., Frank \& Kamp 1997), there is too much.

$(\sim)$

Individual domain
atom
individual (consisting of atoms)
most central
part-whole order $\subseteq_{e}$
$\subseteq_{e}$-greatest individual

\section{Modal domain}

$\begin{array}{ll}\sim & \text { world } \\ \sim & \text { possibility (consisting of worlds) } \\ \sim & \text { closest } \\ \sim & \text { part-whole order } \subseteq_{\omega} \\ \sim & \subseteq_{\omega} \text {-greatest possibility }\end{array}$

The order $\leq_{i}$, defined in (T1), ranks objects $t$ and $u$ of any dref type $a$ by proximity to the $a$-center of the centered world $i$. It says that, viewed from the $a$ center of $i, t$ is at least as close as $u$ just in case the $i$-extension of $u$ contains no elements - atoms or worlds, as appropriate - that are closer to the $a$-center of $i$ than any elements of the $i$-extension of $t$. In other words, the $i$-closer object, $t$, consists only of elements that are closer to the $a$-center of $i$. For individuals and individual concepts - that is, $a \in\{e, E\}$ - the $a$-center of $i$ is its most central individual, $\pi_{1, e}\left(T_{i}\right)$. For possibilities and possibility concepts $-a \in\{\omega, \Omega\}-$ the $a$-center of $i$ is its world coordinate, $w_{i}$.

$$
\begin{array}{ll}
t_{a} \leq_{i} u_{a} \text { ('from the } a \text {-center of } i, t_{a} \text { is at least as close as } u_{a}^{\prime} \text { ) abbreviates } \\
\forall x x^{\prime}\left(x \in t_{a}^{\circ} i w_{i} \wedge x^{\prime} \in u_{a}^{\circ} i w_{i} \wedge x^{\prime} \leq_{i} x \rightarrow x \leq_{i} x\right) & \text { if } a \in\{e, E\} \\
\forall w w^{\prime}\left(w \in t_{a}^{\circ} i w_{i} \wedge w^{\prime} \in u_{a}{ }^{\circ} i w_{i} \wedge w^{\prime} \leq_{i} w \rightarrow w \leq_{i} w^{\prime}\right) & \text { if } a \in\{\omega, \Omega\}
\end{array}
$$

The symbol ' $E$ ' is used here to denote the domain-neutral relation 'is an elementary part of'. In the individual domain, this relates an atom to an individual (singular or plural) it is part of - e.g., ' $x \in t_{a}{ }^{\circ} i w_{i}$ '. In the modal domain, this is the relation between a world and a possibility (class of worlds) it instantiates i.e., ' $w \in t_{a}{ }^{\circ} i w_{i}$ ' reduces to ' $t_{a}{ }^{\circ} i w_{i} w$ '. Following Lewis (1973), I assume that worlds are partly ordered by a primitive relation $w \leq_{i} w^{\prime}$, which ranks $w$ and $w^{\prime}$ by proximity to the world of $i, w_{i}$. Extending this partial order to atoms, $x \leq_{i} x^{\prime}$ ranks $x$ and $x^{\prime}$ by proximity to the most central individual on the top stack of $i, \pi_{1, e}\left(\top_{i}\right)$.

In the same spirit, definition (T2) says that, viewed from the $a$-center of $i, t$ is included in $u$ iff $u$ - the greater object - includes every $i$-closest element of $t$.

$$
\begin{array}{ll}
t_{a} \subseteq_{i} u_{a} \text { ('viewed from the } a \text {-center of } i, t_{a} \text { is included in } u_{a} \text { ') abbreviates } \\
\forall x\left(x \in t_{a}^{\circ} i w_{i} \rightarrow \exists x^{\prime}\left(x^{\prime} \in u_{a}^{\circ} i w_{i} \wedge x^{\prime} \leq_{i} x\right)\right. & \text { if } a \in\{e, E\} \\
\forall w\left(w \in t_{a}{ }^{\circ} i w_{i} \rightarrow \exists w^{\prime}\left(w^{\prime} \in u_{a}{ }^{\circ} i w_{i} \wedge w^{\prime} \leq_{i} w\right)\right. & \text { if } a \in\{\omega, \Omega\}
\end{array}
$$


Given these two ways to rank dref objects, stacks of dref's can be ranked for proximity or size - by pointwise comparison, as in (T3).

$$
\begin{array}{lll}
c \leq_{i} d & \text { iff } & \forall n\left(\pi_{n}(c) \leq_{i} \pi_{n}(d)\right) \\
c \subseteq_{i} d & \text { iff } & \forall n\left(\pi_{n}(c) \subseteq_{i} \pi_{n}(d)\right)
\end{array}
$$

And this, in turn, makes it possible to define a domain-neutral operation of topical maximization, as in (T4) below.

$$
{ }^{\top} D \quad:=\quad \lambda i j\left(\operatorname{Dij} \wedge \forall h\left(D i h \rightarrow \top_{j} \leq_{i} \top_{h} \wedge \top_{h} \subseteq_{i} \top_{j}\right)\right)
$$

Applied to an update $D$, this operation returns a more restricted update relation, denoted by ${ }^{\top} D$, where out of the topical dref's of $D$ only the closest and greatest survive.

\section{Examples: Center vs. Periphery in Correlatives}

We are now ready to represent cross-domain centering parallels in correlative topiccomment structures, by means of parallel semantic representations up to logical type. For example, in the ambiguous Warlpiri correlative (7), the complementizer 'ST' ('same topic') signals the introduction of a topical referent but underdetermines its type. So depending on the context of (7), the topical referent may be an individual - the contextually salient dog that bites the addressee - added by $\mathbf{x}$ in ( $\left.7^{\prime} \mathrm{A}\right)$. Or it may be a possibility — that a dog may bite — added by $\mathbf{p}$ in $\left(7^{\prime} \mathrm{B}\right){ }^{6,7}$

$$
\begin{aligned}
& \text { [ }{ }^{(1)} \text { dog-ERG }{ }^{(2)} \text { ST-3SG.2sG }{ }^{(3)} \text { [bite-NPST you]] } \\
& \text { A. }{ }^{\top}\left({ }^{(1)}\left[\mathbf{x} \mid \operatorname{dog}_{\mathbf{r}}\langle\mathbf{x}\rangle\right] ;{ }^{(2)}\left[\mid \mathbf{d} e \subseteq \mathbf{d} e_{1}\right] ;{ }^{(3)}\left[\mid \text { bite }_{\mathbf{r}}\langle\mathbf{d} e, y o u\rangle\right]\right) \quad \text {; } \\
& \text { B. }{ }^{\top}\left({ }^{(1)}\left[y \mid d \log _{\mathrm{d} \omega}\langle y\rangle\right] ;{ }^{(2)}[\mathbf{p} \mid \mathbf{p} \subseteq \mathbf{d} \omega] ;{ }^{(3)}\left[\mid \text { bite }_{\mathbf{d} \omega}\langle d E, y o u\rangle\right]\right) \quad \text { ?; } \\
& { }^{(4)} \text { [DEM-TOP FUT-1SG.3SG shoot-NPST Me-ERG] } \\
& { }^{(4)}\left[\mid \text { shoot }_{\mathbf{r}}\langle m e, \mathrm{~d} e\rangle\right] \\
& { }^{(4)}\left[\mid \operatorname{shoot}_{\mathbf{d} \omega}\langle m e, d E\rangle\right]
\end{aligned}
$$

In either case the topical stack - here, just one topical dref - undergoes maximization. We'll get back to the details of this below. The resulting topical update combines with the matrix comment by topic-comment sequencing, ?; (read: 'what about it?') - a presuppositional sequencing operator defined for independent purposes in Bittner (2001). This operator is interpreted like ordinary sequencing except for an aboutness presupposition. The intuitive idea is that topic-comment sequencing presupposes that the comment is about the topic. Formally, a sequence of the form $\left(D_{1}{ }^{?} ; D_{2}\right)$ requires that every topical dref introduced in the topic update $D_{1}$ must be picked up by an anaphoric demonstrative in the comment update $D_{2}$.

In $\left(7^{\prime}\right)$ the aboutness presupposition is satisfied by both representations. In ( $\left.7^{\prime} \mathrm{A}\right)$ the topical dref added by $\mathbf{x}$ in the topic update, ${ }^{\top}(\ldots)$, is picked up in the comment update by the demonstrative de. Similarly, in $\left(7^{\prime} \mathrm{B}\right)$ the topical possibility added by $\mathbf{p}$ is picked up by the demonstrative $\mathbf{d} \omega$. In Warlpiri (7) both of these topic-oriented demonstratives are morphologically realized by the same type-neutral form $n g u l a-j u$ - hence the ambiguity. Note that on the possibility-centered reading $\left(7^{\prime} \mathrm{B}\right)$ the aboutness presupposition does not care about the backgrounded dref, 
introduced by $y$ (individual concept). A backgrounded dref may be optionally picked up in the comment, as it is here, but it need not be. The possibility-centered reading of the topic clause - 'If a dog bites you, ...' - would also be felicitous with a comment like '...then I'll be upset'. What would violate the aboutness presupposition would be a topical if-clause without a commenting then-clause. And likewise in the individual domain (recall Hindi (11), and see (12) below).

Returning now to the details of topical maximization, we begin with the possibility-centered reading $\left(7^{\prime} \mathrm{B}\right)$. Here topical maximization just reconstructs the classical ordering semantics for conditionals - the version due to Lewis (1973), with universal quantification over the closest antecedent worlds. To see how it does that, consider the context change potential of the topical update on this reading:

$$
\begin{aligned}
& \left(\top_{7 \mathrm{~B}}\right) \quad{ }^{\top}\left({ }^{(1)}\left[y \mid d \operatorname{dog}_{\mathrm{d} \omega}\langle y\rangle\right] ;{ }^{(2)}[\mathbf{p} \mid \mathbf{p} \subseteq \mathbf{d} \omega] ;{ }^{(3)}\left[\mid \text { bite } e_{\mathbf{d} \omega}\langle d E, y o u\rangle\right]\right) \\
& \left.\equiv \text { (section 2, contextual modal base } \mathbf{B}:=\pi_{1, \omega}\left(\top_{i}\right)\right) \\
& { }^{\top} \lambda i j \exists \mathbf{p} y\left(\mathbf{p} \cdot(y \cdot i)=j \wedge \forall w\left(\mathbf{B} w \rightarrow \operatorname{dog}_{w}\left(y_{w}\right)\right)\right. \\
& \left.\wedge \mathbf{p} \subseteq \mathbf{B} \wedge \forall w\left(\mathbf{p} w \rightarrow \text { bite }_{w}\left(y_{w}, y o u\right)\right)\right) \\
& \equiv \text { (T4) } \\
& \lambda i j\left(\exists \mathbf { p } y \left(\mathbf{p} \cdot(y \cdot i)=j \wedge \forall w\left(\mathbf{B} w \rightarrow \operatorname{dog}_{w}\left(y_{w}\right)\right)\right.\right. \\
& \left.\wedge \mathbf{p} \subseteq \mathbf{B} \wedge \forall w\left(\mathbf{p} w \rightarrow \text { bite }_{w}\left(y_{w}, y o u\right)\right)\right) \\
& \wedge \forall h\left(\exists \mathbf { p } ^ { \prime } y ^ { \prime } \left(\mathbf{p}^{\prime} \cdot\left(y^{\prime} \cdot i\right)=h \wedge \forall w\left(\mathbf{B} w \rightarrow \operatorname{dog}_{w}\left(y^{\prime}{ }_{w}\right)\right)\right.\right. \\
& \left.\wedge \mathbf{p}^{\prime} \subseteq \mathbf{B} \wedge \forall w\left(\mathbf{p}^{\prime} w \rightarrow \text { bite }_{w}\left(y_{w}^{\prime}, \text { you }\right)\right)\right) \\
& \left.\left.\rightarrow \top_{j} \leq_{i} \top_{h} \wedge \top_{h} \subseteq_{i} \top_{j}\right)\right) \\
& \equiv \text { (eliminate } h \text {, rearrange) } \\
& \lambda i j \exists \mathbf{p} y\left(\mathbf{p} \cdot(y \cdot i)=j \wedge \forall w\left(\mathbf{B} w \rightarrow \operatorname{dog}_{w}\left(y_{w}\right)\right)\right. \\
& \wedge \mathbf{p} \subseteq \mathbf{B} \wedge \forall w\left(\mathbf{p} w \rightarrow \operatorname{dog}_{w}\left(y_{w}\right) \wedge \text { bite }_{w}\left(y_{w}, \text { you }\right)\right) \\
& \wedge \forall \mathbf{p}^{\prime}\left(\mathbf{p}^{\prime} \subseteq \mathbf{B} \wedge \exists y^{\prime} \forall w\left(\mathbf{p}^{\prime} w \rightarrow \operatorname{dog}_{w}\left(y^{\prime}{ }_{w}\right) \wedge \text { bite }_{w}\left(y^{\prime}{ }_{w}, \text { you }\right)\right)\right. \\
& \left.\left.\rightarrow \top_{\mathbf{p} \cdot i} \leq_{i} \top_{\mathbf{p}^{\prime} \cdot i} \wedge \top_{\mathbf{p}^{\prime} \cdot i} \subseteq_{i} \top_{\mathbf{p} \cdot i}\right)\right) \\
& \equiv \text { (T3, definition 1) } \\
& \lambda i j \exists \mathbf{p} y\left(\mathbf{p} \cdot(y \cdot i)=j \wedge \forall w\left(\mathbf{B} w \rightarrow \operatorname{dog}_{w}\left(y_{w}\right)\right)\right. \\
& \wedge \mathbf{p} \subseteq \mathbf{B} \wedge \forall w\left(\mathbf{p} w \rightarrow \operatorname{dog}_{w}\left(y_{w}\right) \wedge \text { bite }_{w}\left(y_{w}, \text { you }\right)\right) \\
& \wedge \forall \mathbf{p}^{\prime}\left(\mathbf{p}^{\prime} \subseteq \mathbf{B} \wedge \exists y^{\prime} \forall w\left(\mathbf{p}^{\prime} w \rightarrow \operatorname{dog}_{w}\left(y_{w}^{\prime}\right) \wedge \text { bite }_{w}\left(y_{w}^{\prime}, \text { you }\right)\right)\right. \\
& \left.\left.\rightarrow \mathbf{p} \leq_{i} \mathbf{p}^{\prime} \wedge \mathbf{p}^{\prime} \subseteq_{i} \mathbf{p}\right)\right) \\
& \equiv(\mathrm{T} 1, \mathrm{~T} 2) \\
& \lambda i j \exists \mathbf{p} y\left(\mathbf{p} \cdot(y \cdot i)=j \wedge \forall w\left(\mathbf{B} w \rightarrow \operatorname{dog}_{w}\left(y_{w}\right)\right)\right. \\
& \wedge \mathbf{p} \subseteq \mathbf{B} \wedge \forall w\left(\mathbf{p} w \rightarrow \operatorname{dog}_{w}\left(y_{w}\right) \wedge \text { bite }_{w}\left(y_{w}, \text { you }\right)\right) \\
& \wedge \forall \mathbf{p}^{\prime}\left(\mathbf{p}^{\prime} \subseteq \mathbf{B} \wedge \exists y^{\prime} \forall w\left(\mathbf{p}^{\prime} w \rightarrow \operatorname{dog}_{w}\left(y_{w}^{\prime}\right) \wedge \text { bite }_{w}\left(y_{w}^{\prime}, \text { you }\right)\right)\right. \\
& \rightarrow \forall w w^{\prime}\left(w \in \mathbf{p} \wedge w^{\prime} \in \mathbf{p}^{\prime} \wedge w^{\prime} \leq_{i} w \rightarrow w^{\prime} \leq_{i} w\right) \\
& \left.\wedge \forall w^{\prime}\left(w^{\prime} \in \mathbf{p}^{\prime} \rightarrow \exists w\left(w \in \mathbf{p} \wedge w \leq_{i} w\right\}\right)\right)
\end{aligned}
$$

That is - recasting the bottom line in the more intuitive DRT style format - the topical dependent clause and the matrix comment add the dref objects in $\left(R_{7 B}\right)$ with the conditions listed in $\left(C_{7 B}\right)$. Let us consider each of these in turn. 


$\begin{array}{llll}\left(\mathrm{R}_{7 \mathrm{~B}}\right) & i & j=\left\langle w_{i}, \mathrm{~T}_{j}, \perp_{j}\right\rangle\left(\operatorname{after}^{\top}\left[^{(1)-(3)}\right]\right) & \left.h=j \text { (after comment }{ }^{(4)}\right) \\ \mathbf{d} \omega & \lambda w . \mathbf{B} w & \lambda w . \mathbf{A} w & \lambda w . \mathbf{A} w \\ \mathbf{d} \omega_{1} & \ldots & \lambda w . \mathbf{B} w & \lambda w . \mathbf{B} w \\ d E & \ldots & \lambda w . \mathbf{c}_{w} & \lambda w . \mathbf{c}_{w}\end{array}$

$\left(\mathrm{C}_{7 \mathrm{~B}}\right) \quad$ Topic description at $j$

- $\mathbf{A}=\mathrm{THE}_{i} \lambda \mathbf{p}\left[\mathbf{p} \subseteq \mathbf{B} \wedge \exists y \forall w\left(\mathbf{p} w \rightarrow \operatorname{dog}_{w}\left(y_{w}\right) \wedge\right.\right.$ bite $\left.\left._{w}\left(y_{w}, y o u\right)\right)\right]$

$$
\begin{aligned}
:= & \mathbf{A} \subseteq \mathbf{B} \wedge \exists y \forall w\left(\mathbf{A} w \rightarrow \operatorname{dog}_{w}\left(y_{w}\right) \wedge \text { bite }_{w}\left(y_{w}, y o u\right)\right) \\
& \wedge \forall \mathbf{p}\left[\mathbf{p} \subseteq \mathbf{B} \wedge \exists y \forall w\left(\mathbf{p} w \rightarrow \operatorname{dog}_{w}\left(y_{w}\right) \wedge b_{i t e}\left(y_{w}, y o u\right)\right)\right. \\
& \left.\rightarrow \mathbf{A} \leq_{i} \mathbf{p} \wedge \mathbf{p} \subseteq_{i} \mathbf{A}\right]
\end{aligned}
$$

- $\forall w\left(\mathbf{B} w \rightarrow \operatorname{dog}_{w}\left(\mathbf{c}_{w}\right)\right) \wedge \forall w\left(\mathbf{A} w \rightarrow\right.$ bite $\left._{w}\left(\mathbf{c}_{w}, y o u\right)\right)$

Comment at $h$

- $\forall w\left(\mathbf{A} w \rightarrow \operatorname{shoot}_{w}\left(m e, \mathbf{c}_{w}\right)\right)$

First of all, note that the representation of the initial noun ('dog-ERG') refers to the currently topical possibility (via the demonstrative $d \omega$ ). So for this reference to be felicitous, we need an initial centered world $i$ with a possibility on the top stack. In $\left(\mathrm{R}_{7 \mathrm{~B}}\right)$ this is represented by $\lambda w . \mathbf{B} w$, which plays the domain-restricting role of a contextual modal base. From the initial centered world $i$, the dependent topic clause takes us to a recentered world $j$, by adding another topical possibility, $\lambda w . \mathbf{A} w$ - this demotes the modal base $\lambda w . \mathbf{B} w$ one notch - as well as a backgrounded individual concept, $\lambda w . \mathbf{c}_{w}$.

These two new dref's must satisfy the conditions listed for $j$ in $\left(\mathrm{C}_{7 \mathrm{~B}}\right)$. The first condition says that, viewed from $w_{i}$ - the $\omega$-center of $i-\mathbf{A}$ is the closest and greatest possibility, within the modal base $\mathbf{B}$, such that some individual concept is realized throughout this possibility as a dog that bites the addressee. The first line is a Russell-style abbreviation, while the next three lines spell out what this means.

Well, to qualify as the closest and greatest our topical possibility A must meet two requirements. First, it must be in the set of possibilities at issue. That is, $\mathbf{A}$ is included in the modal base $\mathbf{B}$ and some individual concept is realized throughout $\mathbf{A}$ as a dog that bites the addressee. And secondly, compared to any competing possibility $\mathbf{p}$ that also meets the first requirement, $\mathbf{A}$ ranks as $i$-closer i.e., it contains only $i$-closest worlds - as well as $i$-greater - i.e., it contains all of them.

The second condition on $j$ constrains the topical possibility $\mathbf{A}$ as well as the backgrounded concept $\mathbf{c}$. Throughout the modal base $\mathbf{B}$ the extension of $\mathbf{c}$ must be a dog, and throughout $\mathbf{A} \subseteq \mathbf{B}$ it must be a dog that bites the addressee.

About the new topical possibility $\mathbf{A}$, the matrix comment adds further information, which takes us to $h$ - namely, that in every world of the topical possibility $\mathbf{A}$ the speaker shoots the extension of $\mathbf{c}$, i.e., whatever dog bites there.

So on the possibility-centered reading, at the end of the day, what topical maximization gets us is just a new approach to the classical ordering semantics for conditionals - a reconstruction of Lewis (1973). The virtue of this new approach is that it immediately generalizes to individual-centered readings, such as $\left(7^{\prime} \mathrm{A}\right)$. Once again, we begin by deriving the context change potential of the topical update. 


$$
\begin{aligned}
& \left(\mathrm{T}_{7 \mathrm{~A}}\right) \quad{ }^{\top}\left({ }^{(1)}\left[\mathbf{x} \mid \operatorname{dog}_{\mathbf{r}}\langle\mathbf{x}\rangle\right] ;{ }^{(2)}\left[\mid \mathbf{d} e \subseteq \mathbf{d} e_{1}\right] ;{ }^{(3)}\left[\mid \text { bite }_{\mathbf{r}}\langle\mathbf{d} e, y o u\rangle\right]\right) \\
& \equiv \text { (section } 2 \text {, contextual domain } \mathbf{b}:=\pi_{1, e}\left(T_{i}\right) \text { ) } \\
& { }^{\top} \lambda i j \exists \mathbf{x}\left(\mathbf{x} \cdot i=j \wedge \mathbf{x} \subseteq \mathbf{b} \wedge \operatorname{dog}_{w_{i}}(\mathbf{x}) \wedge \text { bite }_{w_{i}}(\mathbf{x}, \text { you })\right) \\
& \equiv \text { (T4) } \\
& \lambda i j\left(\exists \mathbf{x}\left(\mathbf{x} \cdot i=j \wedge \mathbf{x} \subseteq \mathbf{b} \wedge \operatorname{dog}_{w_{i}}(\mathbf{x}) \wedge \text { bite }_{w_{i}}(\mathbf{x}, \text { you })\right)\right. \\
& \wedge \forall h\left(\exists \mathbf{x}^{\prime}\left(\mathbf{x}^{\prime} \cdot i=h \wedge \mathbf{x}^{\prime} \subseteq \mathbf{b} \wedge \operatorname{dog}_{w_{i}}\left(\mathbf{x}^{\prime}\right) \wedge \text { bite }_{w_{i}}\left(\mathbf{x}^{\prime}, \text { you }\right)\right)\right. \\
& \left.\rightarrow \top_{j} \leq_{i} \top_{h} \wedge \top_{h} \subseteq_{i} \top_{j}\right) \text { ) } \\
& \equiv \text { (eliminate } h \text {, rearrange) } \\
& \lambda i j \exists \mathbf{x}(\mathbf{x} \cdot i)=j \wedge \mathbf{x} \subseteq \mathbf{b} \wedge \operatorname{dog}_{w_{i}}(\mathbf{x}) \wedge \text { bite }_{w_{i}}(\mathbf{x}, \text { you }) \\
& \wedge \forall \mathbf{x}^{\prime}\left(\mathbf{x}^{\prime} \subseteq \mathbf{b} \wedge \operatorname{dog}_{w_{i}}\left(\mathbf{x}^{\prime}\right) \wedge \text { bite }_{w_{i}}\left(\mathbf{x}^{\prime}, \text { you }\right)\right. \\
& \left.\rightarrow \top_{\mathbf{x} \cdot i} \leq_{i} \top_{\mathbf{x}^{\prime} \cdot i} \wedge \top_{\mathbf{x}^{\prime} \cdot i} \subseteq_{i} \top_{\mathbf{x} \cdot i}\right) \text { ) } \\
& \equiv \text { (T3, definition } 1) \\
& \lambda i j \exists \mathbf{x}(\mathbf{x} \cdot i)=j \wedge \mathbf{x} \subseteq \mathbf{b} \wedge \operatorname{dog}_{w_{i}}(\mathbf{x}) \wedge \text { bite }_{w_{i}}(\mathbf{x}, \text { you }) \\
& \wedge \forall \mathbf{x}^{\prime}\left(\mathbf{x}^{\prime} \subseteq \mathbf{b} \wedge \operatorname{dog}_{w_{i}}\left(\mathbf{x}^{\prime}\right) \wedge \text { bite }_{w_{i}}\left(\mathbf{x}^{\prime}, \text { you }\right)\right. \\
& \left.\rightarrow \mathbf{x} \leq_{i} \mathbf{x}^{\prime} \wedge \mathbf{x}^{\prime} \subseteq_{i} \mathbf{x}\right) \text { ) } \\
& \equiv(\mathrm{T} 1, \mathrm{~T} 2) \\
& \lambda i j \exists \mathbf{x}(\mathbf{x} \cdot i)=j \wedge \mathbf{x} \subseteq \mathbf{b} \operatorname{dog}_{w_{i}}(\mathbf{x}) \wedge \text { bite }_{w_{i}}(\mathbf{x}, \text { you }) \\
& \wedge \forall \mathbf{x}^{\prime}\left(\mathbf{x}^{\prime} \subseteq \mathbf{b} \operatorname{dog}_{w_{i}}\left(\mathbf{x}^{\prime}\right) \wedge \text { bite }_{w_{i}}\left(\mathbf{x}^{\prime}, \text { you }\right)\right. \\
& \rightarrow \forall x x^{\prime}\left(x \in \mathbf{x} \wedge x^{\prime} \in \mathbf{x}^{\prime} \wedge x^{\prime} \leq_{i} x \rightarrow x \leq_{i} x^{\prime}\right) \\
& \wedge \forall x^{\prime}\left(x^{\prime} \in \mathbf{x}^{\prime} \rightarrow \exists x\left(x \in \mathbf{x} \wedge x \leq_{i} x^{\jmath}\right)\right)
\end{aligned}
$$

To see what this means in intuitive terms, we again recast the bottom line in the DRT style format and consider each piece in turn.

$$
\begin{aligned}
& \begin{array}{llll}
\left(\mathrm{R}_{7 \mathrm{~A}}\right) & \begin{array}{l}
i \\
\mathbf{d} e
\end{array} \mathbf{b} & \mathbf{b}=\left\langle w_{i}, \top_{j}, \perp_{i}\right\rangle\left(\operatorname{after}^{\top}\left[{ }^{(1)-(3)}\right]\right) & h=j\left(\operatorname{after~comment~}^{(4)}\right) \\
\mathbf{d} & \mathbf{a}
\end{array} \\
& \begin{array}{llll}
\mathbf{d} e_{1} & \ldots & \mathbf{b} & \mathbf{b}
\end{array}
\end{aligned}
$$

$\left(\mathrm{C}_{7 \mathrm{~A}}\right)$ Topic description at $j$

- $\mathbf{a}=\operatorname{THE}_{i} \lambda \mathbf{x}\left[\mathbf{x} \subseteq \mathbf{b} \wedge \operatorname{dog}_{w_{i}}(\mathbf{x}) \wedge\right.$ bite $_{w_{i}}(\mathbf{x}$, you $\left.)\right]$

$$
\begin{aligned}
:= & \mathbf{a} \subseteq \mathbf{b} \wedge \operatorname{dog}_{w_{i}}(\mathbf{a}) \wedge \text { bite }_{w_{i}}(\mathbf{a}, \text { you }) \\
& \wedge \forall \mathbf{x}\left[\mathbf{x} \subseteq \mathbf{b} \wedge \operatorname{dog}_{w_{i}}(\mathbf{x}) \wedge \text { bite }_{w_{i}}(\mathbf{x}, \text { you }) \rightarrow \mathbf{a} \leq_{i} \mathbf{x} \wedge \mathbf{x} \subseteq_{i} \mathbf{a}\right]
\end{aligned}
$$

Comment at $h$

$$
\text { - } \operatorname{shoot}_{w_{i}}(m e, \mathbf{a})
$$

First, parallel to the domain-restricting modal base $B$ presupposed in $\left(R_{7 B}\right)$, in $\left(R_{7 A}\right)$ the domain restriction comes from a presupposed base plurality $b$. Within that domain, topical maximization selects the closest and greatest top stack that 
satisfies the topic description. For ease of comparison with $\left(\mathrm{C}_{7 \mathrm{~B}}\right)$, the first line in $\left(\mathrm{C}_{7 \mathrm{~A}}\right)$ again gives a Russell-style abbreviation while the next two lines spell it out.

To qualify as the closest and greatest our top stack — here, the individual a - must meet two requirements. First, it must be in the set of individuals at issue. That is, $\mathbf{a}$ is part of the contextual base plurality $\mathbf{b}$ and is a dog that bites the addressee. And secondly, compared to any competing individual $\mathbf{x}$ that also meets the first requirement, a ranks as $i$-closer - i.e., it contains only most $i$-prominent atoms - as well as $i$-greater - i.e., it contains all of them.

Depending on the number - singular or plural - the competing individuals will be either all atoms, or else atoms as well as pluralities. Accordingly, topical maximization will select either the unique most prominent atomic individual of the lot, as in ( $\left.7^{\prime} \mathrm{A}\right)$, or else the greatest most prominent plurality. So on the individualcentered reading, topical maximization reconstructs the lattice-theoretic analysis of definite noun phrases developed by Sharvy (1980) and Link (1983) and integrates it with the insights of Groenendijk et al (1995) concerning contextual domain restrictions to currently prominent individuals.

The final example (12), from Hindi, illustrates the need for maximizing stacks, not just dref objects, and for restricting this operation to the top stack only.

$j$ in do laRkoN-ne jis laRkii-ko ek phool diyaa which two boys-ERG which girl-ACC one flower gave ${ }^{\top}\left(\left[\mathbf{x}_{1} \mid \mathbf{x}_{1} \subseteq \mathbf{d} e, 2 b s_{\mathbf{r}}\left\langle\mathbf{x}_{1}\right\rangle\right] ;\left[\mathbf{x}_{2} \mid \mathbf{x}_{2} \subseteq d e, g r_{\mathbf{r}}\left\langle\mathbf{x}_{2}\right\rangle\right] ;\right.$ $\left.\left[x_{3} \mid f l_{\mathbf{r}}\left\langle x_{3}\right\rangle, g i v_{\mathbf{r}}\left\langle\mathbf{x}_{1}, \mathbf{x}_{2}, x_{3}\right\rangle\right]\right)^{?}$

$u$ s laRkii-ne un laRkoN-ko pasand kiyaa. that girl-ERG these boys-ACC like did [ $\left.\mid g r_{\mathbf{r}}\langle\mathbf{d} e\rangle, 2 b s_{\mathbf{r}}\left\langle\mathbf{d} e_{1}\right\rangle, l i k e_{\mathbf{r}}\left\langle\mathbf{d} e, \mathbf{d} e_{1}\right\rangle\right]$

$$
\begin{gathered}
{ }^{\top}\left(\left[\mathbf{x}_{1} \mid 2 b s_{\mathbf{r}}\left\langle\mathbf{x}_{1}\right\rangle\right] ;\left[\mathbf{x}_{2} \mid g r_{\mathbf{r}}\left\langle\mathbf{x}_{2}\right\rangle\right] ;\left[x_{3} \mid f l_{\mathbf{r}}\left\langle x_{3}\right\rangle, g i v_{\mathbf{r}}\left\langle\mathbf{x}_{1}, \mathbf{x}_{2}, x_{3}\right\rangle\right]\right) \\
\equiv \quad\left(\operatorname{section~2,~contextual~domains~} \mathbf{b}:=\pi_{1, e}\left(\top_{i}\right), b:=\pi_{1, e}\left(\perp_{i}\right)\right) \\
{ }^{\top} \lambda i j \exists x_{3} \mathbf{x}_{2} \mathbf{x}_{1}\left(x_{3} \cdot \mathbf{x}_{2} \cdot \mathbf{x}_{1} \cdot i=j \wedge \mathbf{x}_{1} \subseteq \mathbf{b} \wedge \mathbf{x}_{2} \subseteq b\right. \\
\left.\wedge 2 b s_{w_{i}}\left(\mathbf{x}_{1}\right) \wedge g r_{w_{i}}\left(\mathbf{x}_{2}\right) \wedge f l\left(x_{3}\right) \wedge g i v_{w_{i}}\left(\mathbf{x}_{1}, \mathbf{x}_{2}, x_{3}\right)\right)
\end{gathered}
$$

$\equiv(\mathrm{T} 4)$

$$
\begin{aligned}
\lambda i j\left(\exists x _ { 3 } \mathbf { x } _ { 2 } \mathbf { x } _ { 1 } \left(x_{3} \cdot \mathbf{x}_{2} \cdot \mathbf{x}_{1} \cdot i=j \wedge \mathbf{x}_{1} \subseteq \mathbf{b} \wedge \mathbf{x}_{2} \subseteq b\right.\right. \\
\left.\wedge 2 b s_{w_{i}}\left(\mathbf{x}_{1}\right) \wedge g r_{w_{i}}\left(\mathbf{x}_{2}\right) \wedge f l\left(x_{3}\right) \wedge g i v_{w_{i}}\left(\mathbf{x}_{1}, \mathbf{x}_{2}, x_{3}\right)\right) \\
\wedge \forall h\left(\exists x _ { 3 } ^ { \prime } \mathbf { x } ^ { \prime } { } _ { 2 } \mathbf { x } ^ { \prime } { } _ { 1 } \left(x_{3}^{\prime} \cdot \mathbf{x}^{\prime}{ }_{2} \cdot \mathbf{x}^{\prime}{ }_{1} \cdot i=h \wedge \mathbf{x}_{1} \subseteq \mathbf{b} \wedge \mathbf{x}^{\prime}{ }_{2} \subseteq b\right.\right. \\
\left.\wedge 2 b s_{w_{i}}\left(\mathbf{x}_{1}^{\prime}\right) \wedge g r_{w_{i}}\left(\mathbf{x}_{2}^{\prime}\right) \wedge f l\left(x_{3}^{\prime}\right) \wedge g i v_{w_{i}}\left(\mathbf{x}_{1}^{\prime}{ }_{1}, \mathbf{x}_{2}^{\prime}, x^{\prime}{ }_{3}\right)\right) \\
\left.\left.\rightarrow \mathrm{T}_{j} \leq_{i} \top_{h} \wedge T_{h} \subseteq_{i} \top_{j}\right)\right)
\end{aligned}
$$

$\equiv$ (eliminate $h$, rearrange, $\mathrm{T} 3$ )

$$
\begin{aligned}
& \lambda i j \exists x_{3} \mathbf{x}_{2} \mathbf{x}_{1}\left(x_{3} \cdot \mathbf{x}_{2} \cdot \mathbf{x}_{1} \cdot i=j \wedge \mathbf{x}_{1} \subseteq \mathbf{b} \wedge \mathbf{x}_{2} \subseteq b\right. \\
& \wedge 2 b s_{w_{i}}\left(\mathbf{x}_{1}\right) \wedge g r_{w_{i}}\left(\mathbf{x}_{2}\right) \wedge f l\left(x_{3}\right) \wedge g i v_{w_{i}}\left(\mathbf{x}_{1}, \mathbf{x}_{2}, x_{3}\right) \\
& \wedge \forall \mathbf{x}_{2}^{\prime} \mathbf{x}_{1}^{\prime}\left(\mathbf{x}^{\prime}{ }_{1} \subseteq \mathbf{b} \wedge \mathbf{x}_{2}^{\prime} \subseteq b\right. \\
& \wedge 2 b s_{w_{i}}\left(\mathbf{x}_{1}^{\prime}\right) \wedge g r_{w_{i}}\left(\mathbf{x}_{2}^{\prime}\right) \wedge \exists x_{3}\left(f l\left(x_{3}^{\prime}\right) \wedge g i v_{w_{i}}\left(\mathbf{x}_{1}^{\prime}, \mathbf{x}_{2}^{\prime}, x^{\prime}\right)\right) \\
&\left.\left.\rightarrow \mathbf{x}_{1} \leq_{i} \mathbf{x}_{1}^{\prime} \wedge \mathbf{x}_{2} \subseteq_{i} \mathbf{x}_{2}^{\prime} \wedge \mathbf{x}_{1}^{\prime} \subseteq_{i} \mathbf{x}_{1} \wedge \mathbf{x}_{2}^{\prime} \subseteq_{i} \subseteq_{2}\right)\right)
\end{aligned}
$$


In the DRT style format, (12) gives rise to recentering by adding the dref's in $\left(R_{12}\right)$, and also adds or tests factual information via the conditions listed in $\left(C_{12}\right)$.

$\begin{array}{rllll}\left(\mathrm{R}_{12}\right) & & i & j=\left\langle w_{i}, \top_{j}, \perp_{i}\right\rangle\left(\operatorname{after}^{\top}[\ldots]\right) & h=j \text { (after comment) } \\ \mathbf{d} e & \mathbf{b} & \mathbf{a}^{\prime \prime} & \mathbf{a}^{\prime \prime} \\ \mathbf{d} e_{1} & \ldots & \mathbf{a}+\mathbf{a}^{\prime} & \mathbf{a}+\mathbf{a}^{\prime} \\ \mathbf{d} e_{2} & \ldots & \mathbf{b} & \mathbf{b} \\ d e & b & f & f \\ d e_{1} & \ldots & b & b\end{array}$

$\left(\mathrm{C}_{12}\right)$ Topic description at $j$

- $\left\langle\mathbf{a}^{\prime \prime}, \mathbf{a}+\mathbf{a}^{\prime}\right\rangle=\operatorname{THE}_{i} \lambda\left\langle\mathbf{x}_{2}, \mathbf{x}_{1}\right\rangle\left[\mathbf{x}_{1} \subseteq \mathbf{b} \wedge \mathbf{x}_{2} \subseteq b \wedge 2 b s_{w_{i}}\left(\mathbf{x}_{1}\right) \wedge g r_{w_{i}}\left(\mathbf{x}_{2}\right)\right.$

$$
\begin{aligned}
& \wedge \exists x_{3}\left(f l_{w_{i}}\left(x_{3}\right) \wedge g i v_{w_{i}}\left(\mathbf{x}_{1}, \mathbf{x}_{2}, x_{3}\right)\right] \\
&:=\mathbf{a}+\mathbf{a}^{\prime} \subseteq \mathbf{b} \wedge \mathbf{a}^{\prime \prime} \subseteq b \wedge 2 b s_{w_{i}}\left(\mathbf{a}+\mathbf{a}^{\prime}\right) \wedge g r_{w_{i}}\left(\mathbf{a}^{\prime \prime}\right) \\
& \wedge \exists x_{3}\left(f l_{w_{i}}\left(x_{3}\right) \wedge g i v_{w_{i}}\left(\mathbf{a}+\mathbf{a}^{\prime}, \mathbf{a}^{\prime \prime}, x_{3}\right)\right) \\
& \wedge \forall \mathbf{x}_{2} \mathbf{x}_{1}\left[\mathbf{x}_{1} \subseteq \mathbf{b} \wedge \mathbf{x}_{2} \subseteq b\right. \wedge 2 b s_{w_{i}}\left(\mathbf{x}_{1}\right) \wedge g r_{w_{i}}\left(\mathbf{x}_{2}\right) \\
& \wedge \exists x_{3}\left(f l_{w_{i}}\left(x_{3}\right) \wedge g i v_{w_{i}}\left(\mathbf{x}_{1}, \mathbf{x}_{2}, x_{3}\right)\right] \\
&\left.\rightarrow \mathbf{a}+\mathbf{a}^{\prime} \leq \mathbf{x}_{1} \wedge \mathbf{a}^{\prime \prime} \leq_{i} \mathbf{x}_{2} \wedge \mathbf{x}_{1} \subseteq_{i} \mathbf{a}+\mathbf{a}^{\prime} \wedge \mathbf{x}_{2} \subseteq_{i} \mathbf{a}^{\prime \prime}\right]
\end{aligned}
$$

- $f l_{w_{i}}(f) \wedge g i v_{w_{i}}\left(\mathbf{a}+\mathbf{a}^{\prime}, \mathbf{a}^{\prime \prime}, f\right)$

Comment at $h$

- $\quad \operatorname{like}_{w_{i}}\left(\mathbf{a}^{\prime \prime}, \mathbf{a}+\mathbf{a}^{\prime}\right)$

A rough translation of (12) is 'As for the two boys and the girl they gave a flower, that girl liked those boys'. That is, (12) is about the pair of $j$-marked dref's. Accordingly, the matrix comment can satisfy the aboutness presupposition without addressing the backgrounded (ek-marked) flower, and topical maximization targeting the closest and greatest top stack - in effect selects the closest and greatest pair, $\left\langle\mathbf{a}^{\prime \prime}, \mathbf{a}+\mathbf{a}^{\prime}\right\rangle$, of two boys, $\mathbf{a}+\mathbf{a}^{\prime}$, and a girl, $\mathbf{a}^{\prime \prime}$, they gave a flower.

That is - revealing the true generalization behind the pattern of topical maximization we have seen so far - our topical pair $\left\langle\mathbf{a}^{\prime \prime}, \mathbf{a}+\mathbf{a}^{\prime}\right\rangle$ will qualify as the closest and greatest just in case it meets two requirements. First, it must be in the set of pairs at issue. That is, $\mathbf{a}+\mathbf{a}^{\prime}$ is a plurality of two boys contained in a contextual base plurality $\mathbf{b}, \mathbf{a}^{\prime \prime}$ is a girl contained in a (possibly different) base plurality $b$, and $\mathbf{a}+\mathbf{a}^{\prime}$ gave $\mathbf{a}^{\prime \prime}$ a flower. And secondly, compared to any competing pair $\left\langle\mathbf{x}_{2}, \mathbf{x}_{1}\right\rangle$ which also meets the first requirement, pointwise comparison ranks $\left\langle\mathbf{a}^{\prime \prime}, \mathbf{a}+\mathbf{a}^{\prime}\right\rangle$ as $i$-closer - i.e., $\mathbf{a}^{\prime \prime}$ and $\mathbf{a}+\mathbf{a}^{\prime}$ contain only most $i$-prominent atoms - as well as $i$-greater - i.e., they contain all of them.

\section{Conclusion}

Crosslinguistic evidence shows that the semantic parallels between individuals and possibilities are even more pervasive and more detailed than has so far been 
recognized. In addition to the well-known referential and anaphoric parallels, there are centering parallels - revealed by correlative topic-comment structures concerning domain-neutral topical maximization and aboutness presuppositions. These point-for-point parallels across domains can be explicated in all their exquisite detail in a semantic representation language - Logic of Change with Centered Worlds - which integrates theoretical insights drawn from three sources: The Logic of Change of Muskens (1995), the extension to modal anaphora due to Stone (1997), and the related Logic of Change with Centering of Bittner (2001).

This study also illustrates a more general point. When it comes to universal semantics, we can trust every natural language to tell nothing but truth, but we cannot trust any one language to tell the whole truth. There is simply too much to tell. All too often, English-based theories of semantic phenomena are viewed not as just that - stories about English - but as stories about universal semantics. This paper illustrates how dramatically the English-based picture may still be transformed by evidence from typologically distant languages. For this evidence may reveal that the familiar facts of English are just a few pieces of a far bigger pattern - for example, a centering pattern big enough to subsume both definite noun phrases and conditional clauses as manifestations, in different semantic domains, of the same domain-neutral principles of topic-comment articulation.

\section{Endnotes}

I have benefited from conversations with Matthew Stone, Hans Kamp, Kit Fine and other participants in SALT XI, Semantics Group at IMS Stuttgart (May 2000), Tel Aviv workshop on Syntax and Semantics of Relative Clause Constructions and my colloquia at the Center for General Linguistics, Typology and Universals (ZAS) in Berlin and Deparment of Linguistics at UCSC. I also thank my native speaker consultants on West Greenlandic Eskimo (inhabitants of Illorsuit in 1978-9 and Ukkusissat in 1982-4) and Hindi (Rajesh Bhatt, Utpal Lahiri, Anoop Mahajan, Tara Mohanan). This research was supported by the NSF grant BCS-9905600.

1 Abbreviations in the glosses. Agreement: $1=1$ st person, $2=2$ nd person, $3=$ 3rd person, $\mathrm{F}=$ feminine, $\mathrm{M}=$ masculine, $\mathrm{PL}=$ plural, $\mathrm{SG}=$ singular. Case $: \mathrm{ACC}=$ accusative $\mathrm{ERG}=$ ergative, $\mathrm{GEN}=$ genitive, $\mathrm{INS}=$ instrumental, $\mathrm{MOD}=$ modalis, $\mathrm{NOM}=$ nominative. Tense $/$ Aspect : FUT $=$ future, NPST $=$ non-past, $\mathrm{PRG}=$ progressive, $\mathrm{PRS}=$ present, $\mathrm{PST}=$ past. Mood $/$ Mode $: \mathrm{EXP}=$ expected, $\mathrm{IND}^{1}=$ intransitive indicative, $\mathrm{IND}^{2}=$ transitive indicative, $\mathrm{INF}=$ infinitive. Centering: $\mathrm{ST}=$ same topic, $\mathrm{TOP}=$ topic.

2 In Polish but not Eskimo, this use of bare obliques is limited to mass nouns.

3 In both languages, a bare infinitive command is curt (e.g., a master to a slave).

4 Dayal (1996), who focuses on individual-centered correlatives, even goes so far as to deny the kinship with conditional correlatives. But her radical claim, that 'correlatives and conditionals encode fundamentally different dependencies' ( $p$. 198 ), is based on a grammaticality contrast which only shows an orthogonal point 5 to wit, the contrast between topical vs. non-topical NP's (see (11)-(12) below).

5 Further conditions and boxes will be added as they become relevant.

6 The plain part-whole relation, denoted by ' $\subseteq$ ', is interpreted in the usual way:

$$
\begin{aligned}
\left(t_{1} \subseteq t_{2}\right) & :=\lambda i\left(t_{1}^{\circ} i w_{i} \subseteq t_{2}^{\circ} i w_{i}\right) \\
& :=\lambda i \forall a\left(a \in t_{1}^{\circ} i w_{i} \rightarrow a \in t_{2}^{\circ} i w_{i}\right) \quad \text { (a ranges over atoms or worlds) }
\end{aligned}
$$

7 As it stands, my theory does not cover multi-case readings, which involve additional universal quantification over 'cases' (see Kadmon 1990, Dayal 1996). In future work I hope to extend the story to these readings, by positing more abstract types of dref's - perhaps dynamic sa-dref's (à la Stone \& Hardt 1997). 


\section{References}

Andrews, A. (1975) Studies in the Syntax of Relative and Comparative Clauses. $\mathrm{Ph}$. D. thesis, MIT, Cambridge. [Published 1985 by Garland, New York.]

Bittner, M. (2001) 'Surface Composition as Bridging'. Journal of Semantics 18(2) [http://www.rci.rutgers.edu/ mbittner/Pages/DynamicXLS.html].

Cooper, R. (1979) 'The Interpretation of Pronouns'. Syntax and Semantics 10, 61-92. Academic Press, New York.

Dayal, V. (1996) Locality in WH Quantification. Kluwer, Dordrecht.

Dekker, P. (1994) 'Predicate Logic with Anaphora'. Proceedings from SALT IV, 79-95. CLC, Cornell University.

Fintel, K. von (1994) Restrictions on Quantifier Domains. Ph. D. dissertation, University of Massachusetts at Amherst.

Frank, A. and H. Kamp (1997) 'On Context Dependence in Modal Constructions'. Proceedings from SALT VII, 136-168. CLC, Cornell University.

Groenendijk, J., M. Stokhof and F. Veltman (1995) 'Coreference and Contextually Restricted Quantification'. Proceedings from SALT V, 112-129. CLC, Cornell University.

Grosu, A. and F. Landman (1998) 'Strange Relatives of the Third Kind'. Natural Language Semantics 6:125-170.

Grosz, B., A. Joshi and S. Weinstein (1995) 'Centering: A Framework for Modeling the Local Coherence of Discourse'. Computational Linguistics 21:203-225.

Haiman, J. (1978) 'Conditionals are Topics'. Language 54:564-589.

Hale, K. (1976) 'The Adjoined Relative Clause in Australia'. In R. Dixon (ed.) Grammatical Categories in Australian Languages, 78-105. Australian Institute of Aboriginal Studies, Canberra.

Kadmon, N. (1990) 'Uniqueness'. Linguistics and Philosophy 13:273-324.

Kamp, H. and U. Reyle (1993) From Discourse to Logic. Kluwer, Dordrecht.

Kaplan, D. (1978) 'On the Logic of Demonstratives'. Journal of Philosophical Logic 8:81-98.

Lewis, D. (1973) 'Counterfactuals and Comparative Possibility'. Journal of Philosophical Logic 2:418-446.

Link, G. (1983) 'The Logical Analysis of Plurals and Mass Terms: A LatticeTheoretic Approach'. In R. Bäuerle et al (eds.) Meanings, Use and the Interpretation of Language, 302-323. de Gruyter, Berlin.

McCawley, J. (1992) 'Remarks on Adsentential, Adnominal and Extraposed Relative Clauses in Hindi'. Presented at South Asian Languages Analysis, Stanford University.

Muskens, R. (1995) 'Tense and the Logic of Change'. In U. Egli et al (eds.) Lexical Knowledge in the Organization of Language, 147-184. John Benjamins, Philadelphia.

Partee, B. (1973) 'Some Structural Parallels between Tenses and Pronouns in English'. Journal of Philosophy 70:601-609.

Schlenker, Ph. (1999) Propositional Attitudes and Indexicality: A Cross-Categorial Approach. Ph. D. dissertation, MIT, Cambridge.

Sharvy, R. (1980) 'A More General Theory of Definite Descriptions'. The Philosophical Review 89:607-624

Stalnaker, R. (1975) 'Indicative Conditionals'. Philosophia 5:269-286.

Stone, M. (1997) 'The Anaphoric Parallel between Modality and Tense'. Technical Report IRCS 97-6. [http://www.cs.rutgers.edu/ mdstone/compsem.html]

Stone, M. and D. Hardt (1997) 'Dynamic Discourse Referents for Tense and Modals'. Proceedings of IWCS II, 287-299. [http://www.cs.rutgers.edu/ mdstone/compsem.html] 